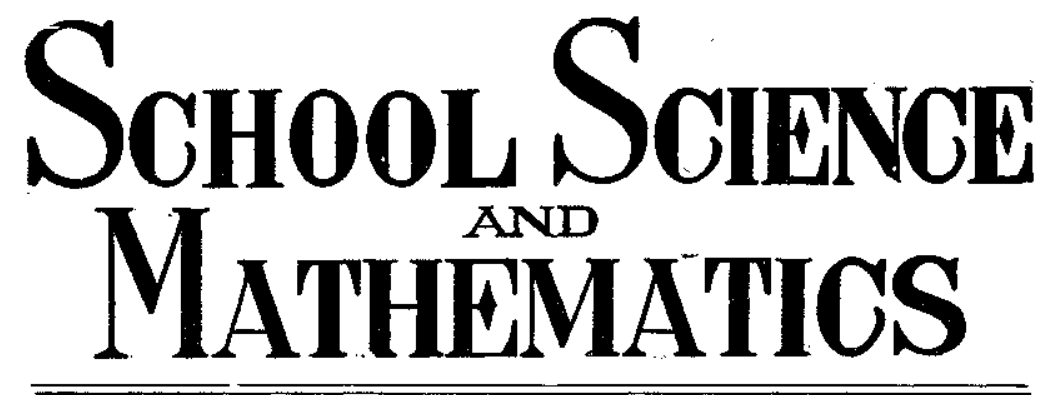

Vol. XXI, No. 1

JANUARY, 1921

WHOLE No. 174

\title{
SOME STUDIES OF CHILDREN'S INTERESTS IN SCIENCE MATERIALS.
}

By Chas. W. Finley,

The Lincoln School of Teachers College, Columbia University.

In an attempt to get some data on the nature of children's interests in animals an experiment was made in schools in three cities and the results recorded in an unpublished thesis. Since that time the same method of collecting information has been extended to three other cities and seven rural schools. In the same investigation an attempt was made to obtain data regarding children's interests in three phases of science work, namely, plants, animals, and physical phenomena. The results as given in the thesis and those obtained in the succeeding investigations are included in this report.

\section{Purpose of the Experiment.}

The inclusion of any particular science material in any of the grades is almost invariably justified on the ground that it is of peculiar interest to children of that grade. If special emphasis is given plant life in the fourth grade it is because ehildren of this grade are "most interested in plants." In another fourth grade in the same city animal life may be the thing emphasized for the same reason. Probably in most instances the peculiar interests of the teachers are the real guiding principles underlying the organization of elementary science materials. In one of the schools investigated the teacher of the second grade emphasized the study of the life history of ants because she had discovered that pupils of that grade were "most interested in the life histories of animals." In the fourth and fifth grades in the same building they were studying the life histories of animals for the same reason. Various grades have made special studies of fish, snakes, trees, chickens, spore plants, spring flowers, pets, electricity, work of running water, seed dispersal, plant propagation, each being 
justified on the basis of peculiar interest to the group of children concerned. Elementary science in some schools means a study of animals and animal life, in others very little of this is done, the main emphasis being given to the study of plants and plant life. In most of the schools plant life and animal life are the only phases of the work included in the course of study. It was the purpose of the investigation to discover whether by experimental procedure data might be obtained which would give evidence regarding the nature of (I.) children's interests in animals and in (II.) the three phases of science work, plants, animals, and physical phenomena.

\section{Children's Interest in Animals.}

The Animal Used.

In planning this part of the experiment it was thought best to use some animal unknown or little known to most of the children. Special attempt was made to conduct the work as nearly as possible under regular school practices. One of the most widely distributed of the North American salamanders was chosen. The animal is technically known as Necturus maculatus and popularly known by such names as "Water-dog," "Mud-puppy," "Water Newt," "Mud Eel," "Gilled Salamander," and "Water Lizzard." In maturity it reaches a length of a little more than a foot. It is a smooth, slimy animal possessing an elongated, flabby

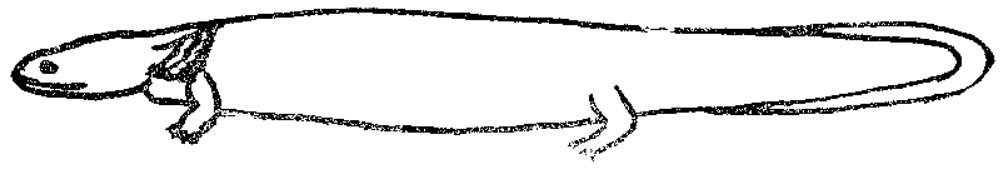

trunk, supported by four weak legs, which seem out of all due proportion to the rest of the animal. The flat head is connected to the trunk by a short, slightly constricted neck and is equipped with two small eyes and a very large mouth. On each side of neck is a three-parted external gill. The animal has a long, compressed tail, bordered with a continuous median fin-like projection or fold of skin. It lives in the mud, weeds, and rocks at the bottoms of streams, feeding on crayfish, frogs, worms small fish, and other water forms. The animal, although repulsive in appearance, is absolutely harmless. In some localities it is superstitiously supposed to be poisonous. In early spring it is often caught on hooks by fishermen. I have known of instances of fishermen cautiously killing the "deadly thing" with a club before removing it from the hook. To one who has never seen it and who has a horror of "creeping things" the animal would undoubtedly present a very unattractive appearance. 


\section{Method of Conducting the Experiment.}

Throughout the whole experiment the work was done in classrooms during regular school hours. A live animal was used. It was housed in three inches of water in a large, rectangular glass aquarium. A repetition of the instructions given the pupils just prior to the demonstration will at the same time explain the plan and show the procedure. The instructions were given orally as follows: "Just outside the door in a large glass jar I have an animal in some water. I am going to bring it into the room and let you see it. No doubt as you look at the animal there will be many questions you would like to ask concerning it. If I am able to do so I shall tell you all you wish to know about it. Before I bring it in, however, there are some favors I wish to ask of you. As you look at the animal you are to ask no questions of each other, of your teacher, or of me. You are to make no suggestions whatever; simply look and think but keep quiet. After you have looked at it for a while you are to take your seats and write as many questions concerning it as you wish. If there is only one thing you wish to know about it, write one question. If there are twenty things you wish to know, write twenty questions. Do not be afraid of asking too many questions. After your papers are collected I shall try to answer the questions you have asked." (In the first and second grades the pupils were told that the teacher and the writer would come to them and they should whisper their questions.)

The animal was then taken into the room, placed on a chair, and about seven pupils at a time were permitted to come and look at it. Three minutes were given each group for observation after which the pupils were requested to take their seats, write their questions, and another group permitted to observe the animal. After the last group had seen it, in all save a few instanees the animal was taken from the room. This method gave the first groups more time for writing their questions; however, ample time was given the last group for writing all the questions desired by the pupils. After the papers were collected a short talk was given concerning the animal; its name, where it could be found, its life history, function of some of its parts, its habits, etc. In order to make sure that no questions were overlooked in the talk, the pupils were given opportunity to state any of their written questions which had not been discussed. In the Elementary School of The School of Education, University of Chicago, grades six to eight were called together for a morning 
assembly in which the discussion of the animal was given. Other than this, the procedure was as stated above.

The precautions in having the pupils in grades one and two whisper their questions and in permitting no remarks during the observation period in the other grades were taken in order that the individual reactions of each pupil, as free as possible from outside influence, might be obtained. An oral suggestion by one pupil during the observation period might result in the initiation of many questions in the minds of the other pupils. It is not meant by this remark that numerous questions were not desired, but that the questions obtained should be the result of each pupil's own reaction. The questions thus obtained were taken as a fair indication of the children's various interests in the animal.

Before taking up a discussion of the results it will probably be in order to list the various schools in which the experiment was tried.

\section{School Types Used.}

School A. The Elementary School of The School of Education, University of Chicago. This is a private school whose pupils are accepted from a list of applicants by the administrative officers. This manner of selection places these pupils as a "selected group." The elementary science of the school at the time of the study was under the direction of the Natural Science Department of The School of Education. The work in the sixth, seventh, and eighth grades was at the time of the experiment taught by a special teacher of the subject. In the first, second, third, and fifth grades the science work was done by the regular teachers in charge of the grades.

School B. The Emerson School, Gary, Indiana. In this school build ing were found all the grammar grades and the four years of the high school. The science teaching was done by special teachers; one had charge of the work in the first five grades, and the regular teachers of botany and zoology in the high school had charge of the work in the remaining grades. In all the grades above the fourth the boys and girls were taught in separate classes.

School C, Oak Park, Illinois. This suburb of Chicago is characterized by a large percentage of good homes and prides itself on its excellent schools. In the ward school in which the experiment was tried the science was taught by the regular grade teachers.

School D. A school in a congested Jewish district in Chicago. This school is located in one of the most congested regions of the 
whole city. The principal estimates that at least ninety-five per cent of the pupils in the school are Jewish. It is far removed from field conditions and little science teaching was attempted at the time of the experiment.

School E. A composite made up of seven rural schools. These schools are located in Coles County, Illinois. Much of the township in which the schools are located is in the rich, black prairie region of the state. The Kaskaskia River flows through part of the district and exposes many square miles of the clay subsoil, hence in the township are found both rich and poor farming regions. Four of the schools are located in the rich farming region and three in the poor. They are all one-room sehools. At the time the experiment was made science was taught in none of them.

School F. Goshen, Indiana. A residential town in northern Indiana with a population of a little less than ten thousand. It had good school buildings, a progressive superintendent, and good teachers. Science was taught in each grade by the teacher in charge.

School G. DeKalb, Illinois. At the time the experiment was made there was a very close cooperation between the State Normal School located there and the city schools. The Head of the Training Department in the normal school was also the Superintendent of City Schools. The experiment was tried in the lower grades of the training school and in the upper grades of one of the ward schools of the city. Science was taught by the regular teachers.

This list of schools presents a wide range in types; from a school in the most congested district of a large city to schools in a secluded rural district; a school in a new city with a new school system organized on nonconventional lines to one of long standing in which the superintendent took great pride in the long tenure of most of his teachers; a school in which most of the pupils were of well-to-do parents and one in which most of the children were of parents of meagre means; a school in which nearly all the pupils were of one race, one in which there were an exceeuingly large number of nationalities, and others in which nearly all the children were of native-born parents; a school having a definitely organized course in elementary science with special teachers to do most of the teaching of it, one having special teachers to do all of it but with no definitely organized course, some having the work taught by the regular teachers and still others having no elementary science at all. 
Sample Pupil Responses With Classification Headings.

Below are some sample papers received from pupils. The spelling is given as it appeared on the papers. The words in parentheses following the questions indicate the classification given the various questions.

Third Grade Pupil:

What is its name? (Identification)

Is it from the South? (Geographical Distribution)

Was it brought from the wild country? (Geographical Distribution)

Where did you get it? (Environment)

How old is it? (Life History)

What does it eat? (Food)

Can it swim very well? (Movements)

What all can it do? (Habits)

Fourth Grade Pupil:

What is the animal? (Identification)

What does it eat? (Food)

Where does it live? (Environment)

Where did you get it? (Environment)

What does it do? (Habits)

What kind of food does it eat? (Food)

\section{Fifth Grade Pupil:}

What kind of animal is it? (Classification)

What does it eat? (Food)

What do you call it? (Identification)

What has it got on its ears? (Gills)

What has it got with him? (Unclassified)

From what country did you get it sir? (Geographical Distribution)

Does he drink the water in which he lives? (Food)

Is he very old? Or is he young? (Life History)

What is he man, or women? Please answer me because I want to know. (Sex)

Sixth Grade Pupil:

What is the name of the animal? (Identification)

What are those things by his ears? (Gills)

What makes them move all the time? (Function of parts)

Must it only live in the water? (Adaptations)

Where are those animals found? (Environment)

Must you change the water every day? (Unclassified)

What does it eat? (Food)

Does it stay in one place all the time? (Habits)

Can you tell how old it is? (Life history)

Has it any teeth? (Structure)

Has it any ears? (Strueture)

What time of day does it go to sleep? (Habits)

Can it swim? (Movements)

What kind of climate does it stay in? (Geographical Distribution)

How did you eatch it? (Unclassified)

What country does it stay in? (Geographical Distribution)

How long is it? (Size)

Can it walk around? (Movements)

How long does it stay in one place? (Habits)

Eighth Grade Pupil:

What are the six pieces on!both'sides of the head? (Gills)

Do they act as breathing apparatus or are they just his ears? (Fuyction of parts) (Structure)

Where are these animals found? (Environment) 
What is its name? (Identification) tory)

In its course of life does it go through different stages of life? (Life his-

What are those lines on the under side of its body? (Structure)

Do they act as helpers to move, or is it just because of its fatness? (Function of parts)

Is it related to the crocodile? (Classification)

From what species of animal does it come? (Classification)

Is it a mammal or not? (Classification)

In tabulating the questions it was found that they concerned the following things: Identification, Classification, Environment, Food, Life History, Adaptations, Movements, Geographical Distribution, Use, Habits, Structure, Gills, Function of Parts, Enemies, Abundance, Sex Color, Evolution, Dangerousness, and Teleological questions.

\section{Number of Pupils Participating.}

The following tables showing the numbers of pupils in the various grades participating in the experiment, the numbers of questions asked in these grades, and the average numbers of questions per pupil in the various grades is needed for a proper interpretation of the graphs which follow.

Schools and Number of Pupils Involved.

$\begin{array}{cccc}\text { Grade } & \text { Number of } & \begin{array}{c}\text { Number of } \\ \text { Questions }\end{array} & \begin{array}{c}\text { Average per } \\ \text { Pupil }\end{array} \\ 1 & \text { Pupils } & 361 & 2.3 \\ 2 & 156 & 365 & 2.8 \\ 3 & 131 & 738 & 3.7 \\ 4 & 197 & 1275 & 5.4 \\ 5 & 238 & 1110 & 5.8 \\ 6 & 192 & 1345 & 5.7 \\ 7 & 237 & 1843 & 5.7 \\ 8 & 322 & 1292 & 5.3\end{array}$

First Second Third Fourth Fifth Sixth Seventh Eighth Total

\begin{tabular}{|c|c|c|c|c|c|c|c|c|}
\hline Grad & & & & & & & & \\
\hline 31 & 46 & 28 & 43 & 43 & 25 & 39 & 49 & 304 \\
\hline $\operatorname{ark} \ldots \ldots . . . .35$ & 17 & 30 & 32 & 32 & 21 & 50 & 36 & \\
\hline .... 29 & 8 & 49 & & & & & & \\
\hline 28 & 34 & 3 & 4 & & & & & \\
\hline & & & 2 & 1 & & 8 & & \\
\hline ......... & & & & & & 4 & & \\
\hline lb......... 2 & 17 & 1 & 45 & 28 & 22 & 38 & 15 & \\
\hline al.......15 & & & & 192 & 237 & 322 & 243 & \\
\hline
\end{tabular}

A Tabulation of the Data in the Form of Graphs.

The following graphs show the result of the tabulation of the data collected. They are used to indicate the interests of the pupils as manifested by the questions asked. The grades are designated by Roman numerals placed at the bottom of the graphs and the indicated per cent of interest in the various phases by Arabic numerals placed at the side. This "per cent of interest" is found by using the number of pupils in the grade 
as a base and the number of questions asked concerning the phase in question as the per cent. For example, if in a grade of twenty pupils, ten questions pertaining to "Function of Parts" were asked the graph should show a fifty per cent interest in this phase, should forty questions have been asked then the graph should show a two hundred per cent interest. A central tendency was found by similarly using all the questions pertaining to any particular phase asked in all the schools in a given grade. This central tendency is designated by a heavy continuous line. Cross hatchured lines indicate coalesence of two or more graphs at that point.

The various schools are designated in the graphs by the following lines:

School A. University Elementary School. Continuous fine line.

*School B. Gary, Indiana. Dash and three dots.

School C. Oak Park, Illinois. Dash and two dots.

School D. Chicago, Mlinois. Dash and one dot.

School E. Rural Schools, Coles County, Illinois. Dashes.

**School F. Goshen, Indiana. Dotted.

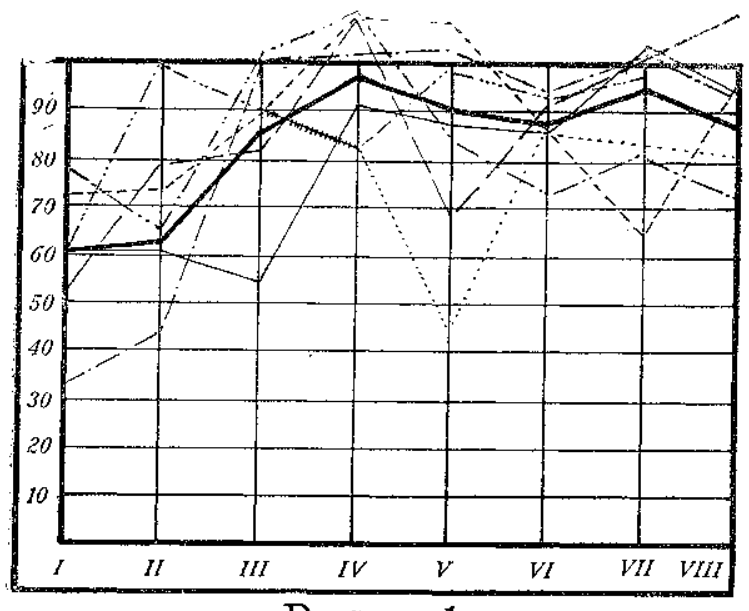

Diagram 1.

Identification. Diagram 1. Under this head were classified such questions as: "What is it?"; "What animal is that?"; "What is that thing?" It will be noticed that all these are simply requests for the name of the animal. The distribution of curves show that by far the greater number of pupils asked this question. On most of the papers this type of question was the first asked.

*It will be noted that this curve ends in the seventh grade in each graph.

**This curve begins in the third grade in each graph. 
Classification. Diagram 2. Classifieation is somewhat related to but differs from identification in that it refers to a grouping of like things rather than to a mere name. Such questions as: "Is it a kind of crocodile?"; "What kind of an animal is it, I mean to what group does it belong?"; "Is it any relation to a frog?" were considered as an indication of interest in classifica-

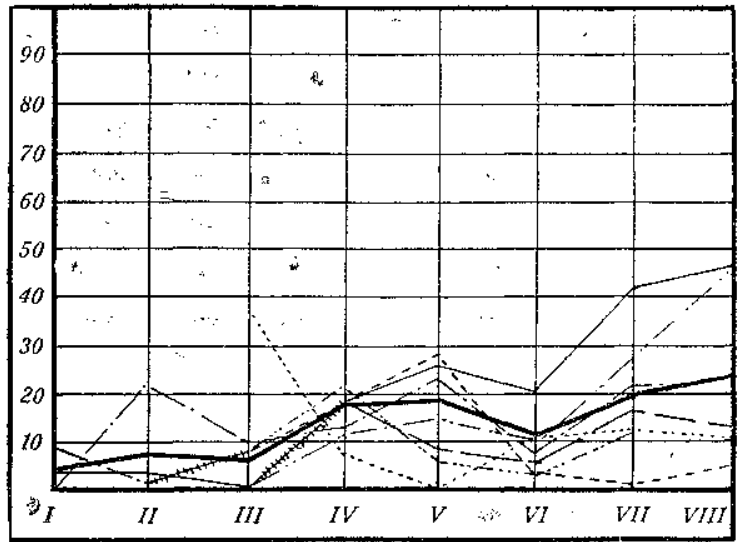

DIAGRAM 2.

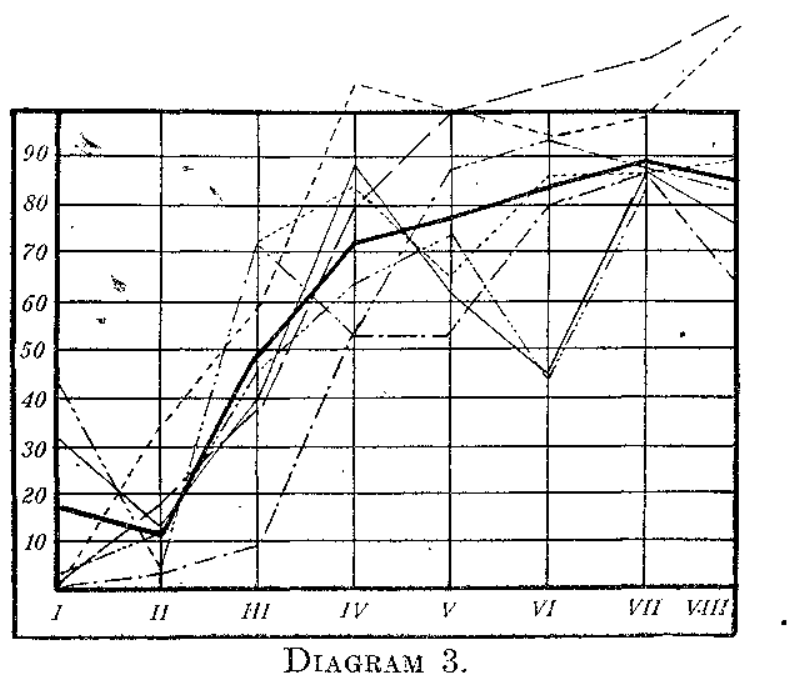

tion. It is probable that very few pupils werc interested in getting its classification from a strict viewpoint of evolutionary sequence but merely to learn its, "grouping with known animals," According to a distribution of the questions but little interest is manifest in this phase below the fourth grade, and only a slight interest in those abovo. 
Environment. Diagram 3. The numbers of questions asked which were taken as an indication of an interest in the place in which the animal lived amounted to less than a fifth of the pupils in grades one and two, three-fourths of the number of pupils in the third grade, and in all the other grades a still larger number. A few type questions are: "Is it found in a lake?"; "Where does it live?"; "Does it live in the water?"

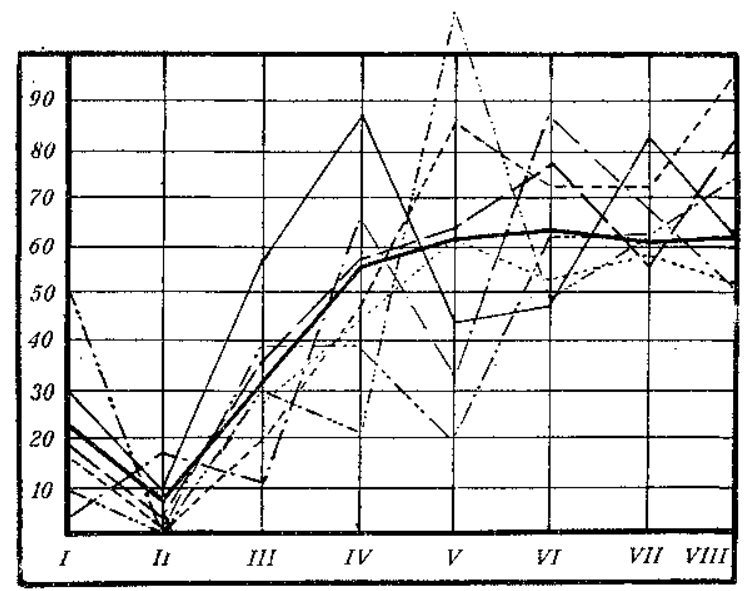

Diagram 4.

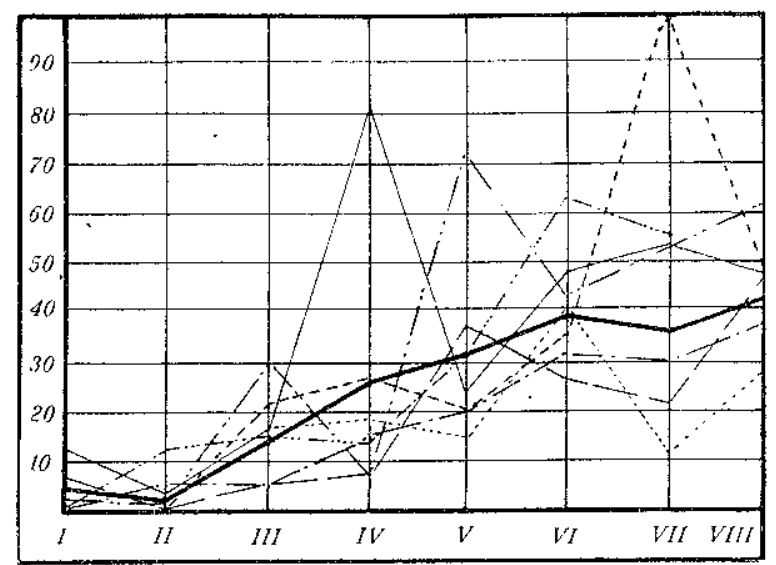

Diagram 5.

Food. Diagram 4. Under this head were classed such questions as pertained to the kind of food eaten by the animal and to the manner of obtaining it. Here again the trend shows little manifested interest in the lower grades, much in the upper with little variation in grades four to eight. By noting the grouping 
of the questions on some of the papers it was found that there might be two types of interest pertaining to food, one signifying a desire of owning the animal as a pet and wanting to know what to feed it, the other signifying a probable economic interest as might be involved in the question, "Does it eat fish?"

Life History. Diagram 5. "Does it have any babies?" "Does it lay eggs?" "Does it cver turn into anything else?"

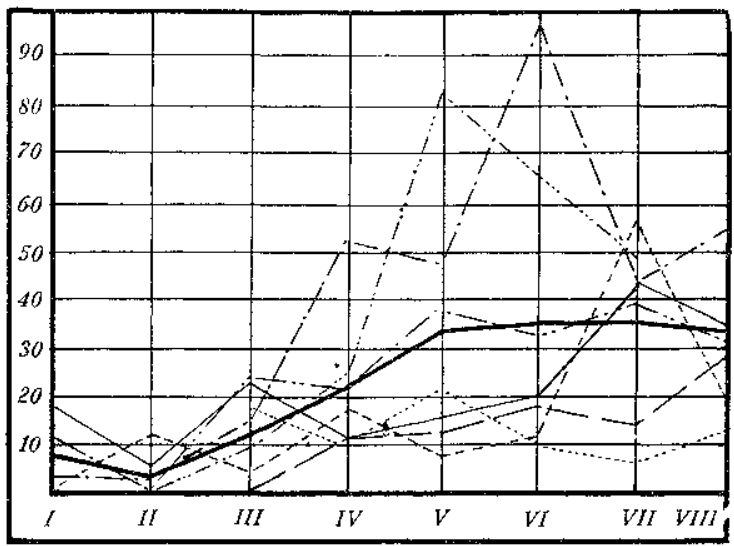

DIAGRAM 6.

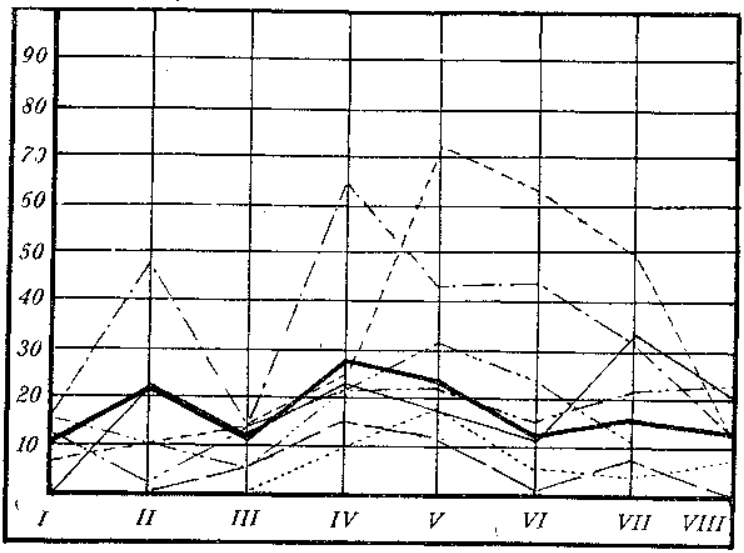

Diagram 7.

Such questions as these were eonsidered as signifying an interest in the life history of the animal. Here, too, there is an indication of a rise in interest in the upper grades. It will be seen that the fourth grade in the University Elementary School, the fifth grade in the Oak Park school, and the seventh grades in the rural schools manifested striking interest in this phase. The fourth grade had just finished a series of lessons on the life his- 
tories and habits of spiders and it is possible that this fact may have had much influence on that curve.

Adaptations. Diagram 6. Questions such as: "Can it live on land as well as in the water?"; "Must it live only in the water?"; "Will hot weather hurt it?" were considered as indicating an interest in the above phase. The graph shows an increase in interest in the successive grades.

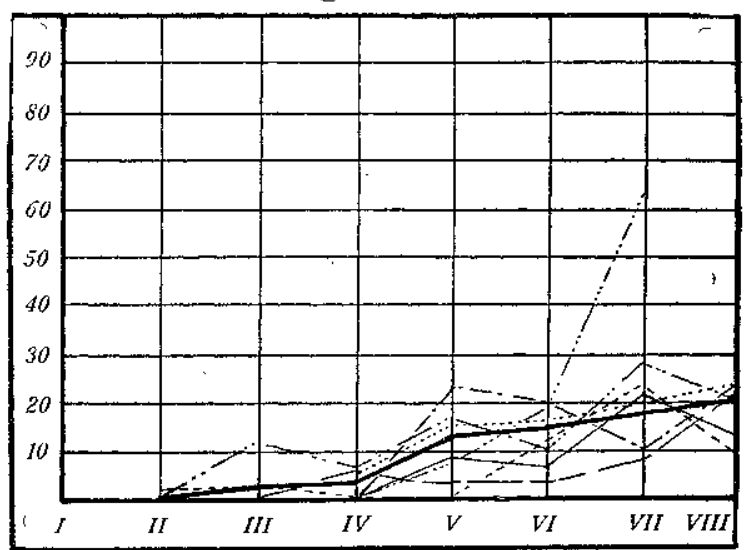

DIAGRAM 8.

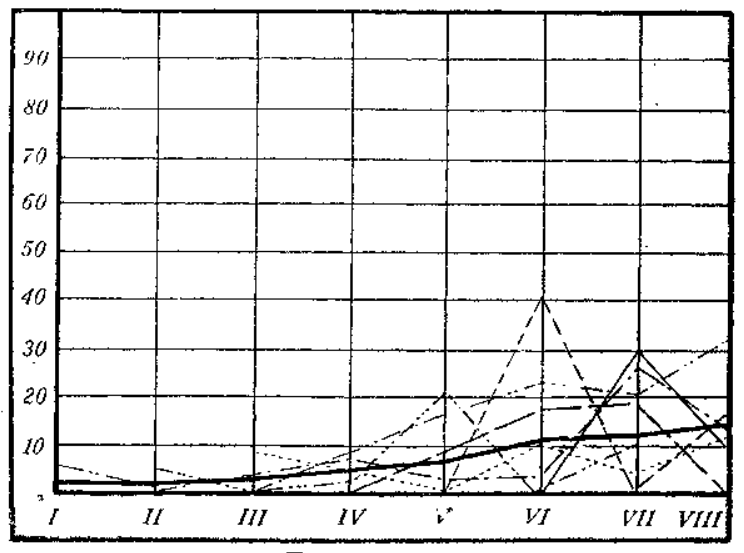

Diagram 9.

Movements. Diagram 7. With the exception of the ward school in Chicago and the rural schools not many questions pertaining to the movements were asked. Grades four and five show most interest in it.

Geographical Distribution. Diagram ${ }_{-1}^{5}$. "In what countries is it found?" Does it live anywhere outside of the United States?" Such questions were classified as "indicated. Not a 
single question of this kind was asked in the first grade and but very few in the second. Not till the fifth grade is reached did the number of such questions asked equal more than five per cent of the number of the pupils in the class. From the fifth grade there was a manifest increase in interest in the phase to the eighth grade where the central tendency line reaches twenty-one per cent.

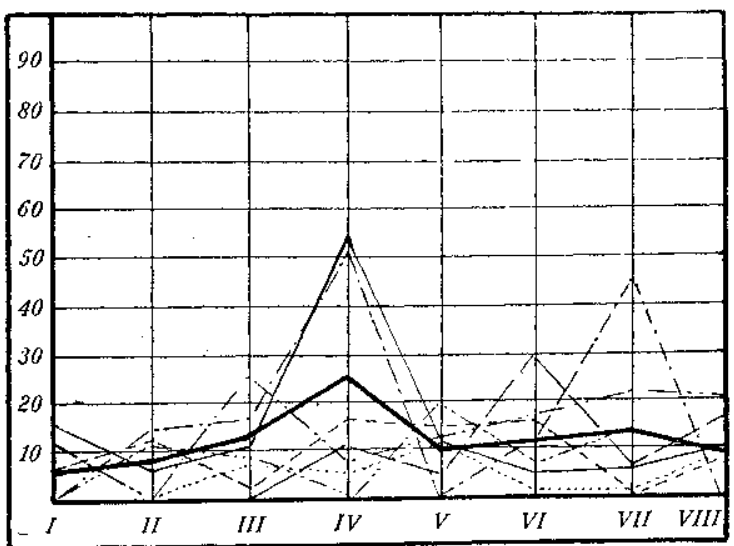

DIAGRAM 10.

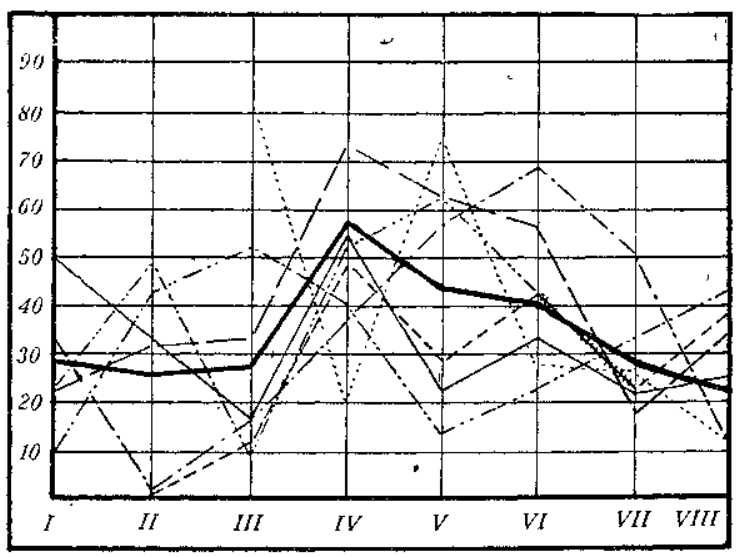

Dragram 11 .

Use. Diagram 9. Under this head were classed such questions as, "Is it of any use to man?"; "Is it good to eat?"; Does its skin make good leather?"; "What is its value?" These questions pertain definitely to an economic interest in the animal. The graph very closely approximates the one above. 
The graphs" pertaining to environment, food, life history, adaptations, classification, geographical distribution, and use agree in showing a designated increase in interest in the succes sive grades. It should be noted, however, that there is a lowering of the graph in the order mentioned above. The curves of distribution are high in the "Environment" graph but very low in the "Use" graph.

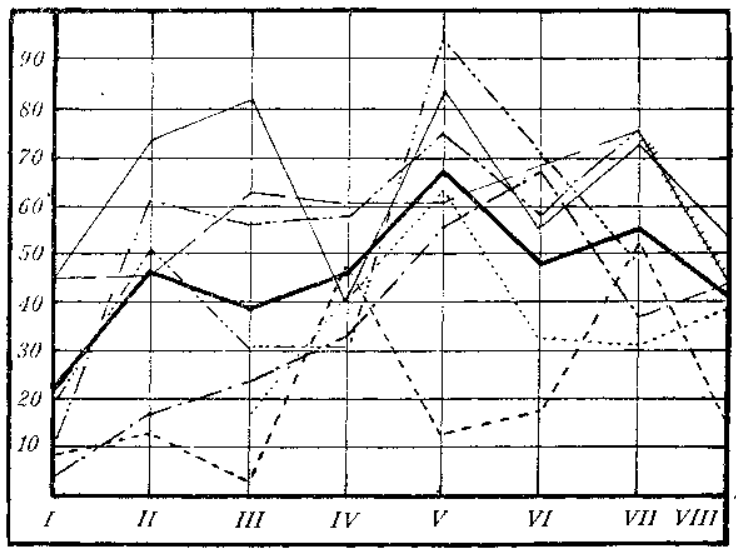

DIAGRAM 12.

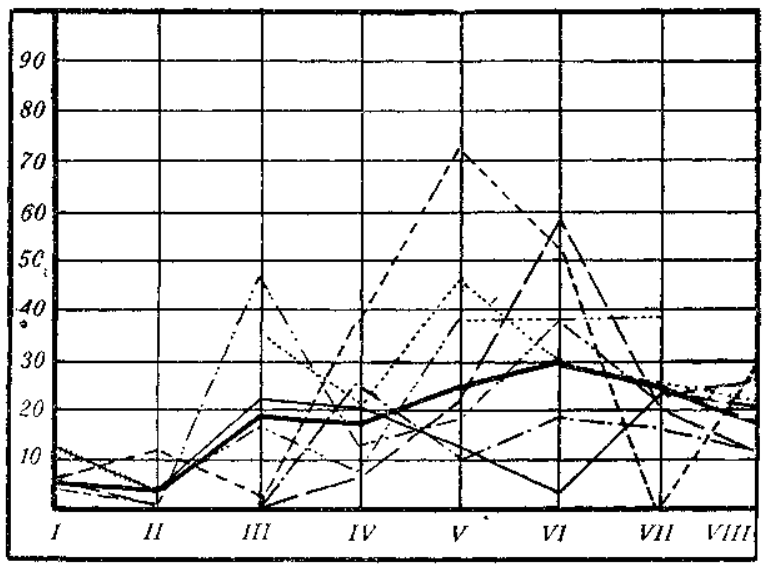

DIAGRAm 13.

Habits. Diagram 10. Under this caption were elassed such questions as, "What are his habits?"; "How does he build his home?" As the skew in of the central tendency curve in the fourth grade is due to the large number of questions asked in two schools the interest manifested in this phase shows little variation throughout the grades. 
Structure. Diagram 11. All questions pertaining to the various structures of the animal save those conceming the gills were graphed with the result, sbown in the diagram. The fourth, fifth, and sixth grades showed most interest in this phase.

Gills. Diagram 12. The gills of the animal are so bizarre and so conspicuous that, although definitcly "Structures," they were classified separately. They might well have been labelled,

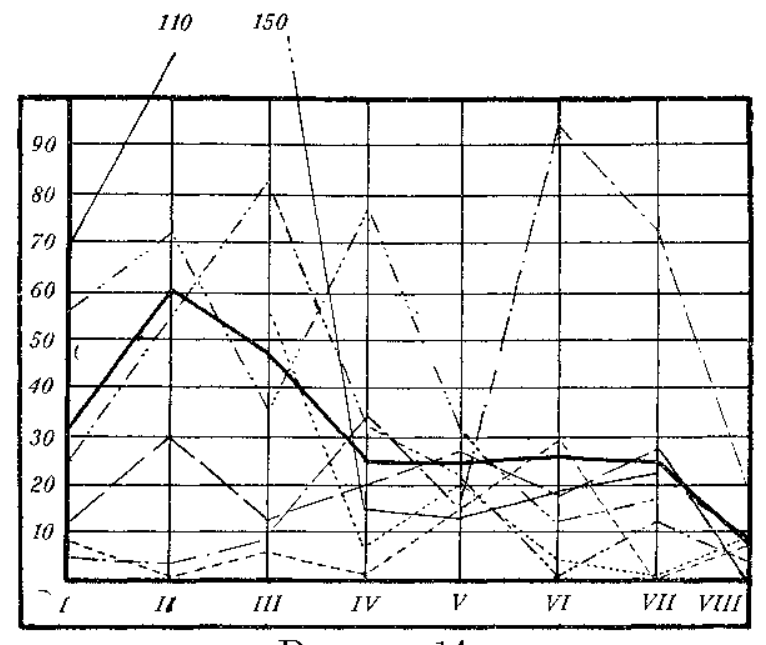

DIAGRAM 14

"Exceedingly Striking Structures" or "Extraordinary Structures." The pupils in the first four grades did not seem to recognize them as extraordinary.

Questions pertaining to function of parts, enemies, abundance, sex color, and evolution were few and the distributions of them failed to show differentiation from which definite conclusions might be drawn.

Dangerousness. Diagram 13. It has been stated that the first reaction of a city boy to an unknown animal is to find out if the animal is dangerous and immediately lay plans to get rid of it. All the children concerned in this report save those in the rural schools mentioned above are city children and a perusal of the graph will show that the contention stated above is not here substantiated. It would have been interesting to have tabulated the questions of the teachers regarding this point. Teachers as a rule were the ones demonstrating fear, not the children. Only twice in all the grades in all the schools did a grade have a number of questions as large as half the number of pupils in the class. 
In the first grade of the University Elementary School during the discussion one of the girls asked if the animal would bite. She was told that it would not. On this occasion the animal was still in the room and the writer inadvertently reached down and stroked the animal. Immediately her hand went up again and she asked if she might not come up and touch the animal. The teacher reluctantly gave the desired permission and before the girl could reach the aquarium a boy had asked permission to do the same. The rest of the pupils did not wait to get permission but came in a group and crowded around the jar trying to touch and pick up the animal. The teacher was much surprised to see the children eager to touch an animal which caused her to shudder when she first looked at it. One little boy insisted on returning to the aquarium after the teacher had told the pupils to take their seats. He remarked, "I only got to touch it and I want to pick it up." In the fourth grade of one school a pupil asked if she might touch the animal. She was told that she might do as she wished. She and a few others in that grade were seen to touch it. A perusal of the graph seems to show that fear of animals is a thing taught the pupils as it is more manifest in the successive grades.

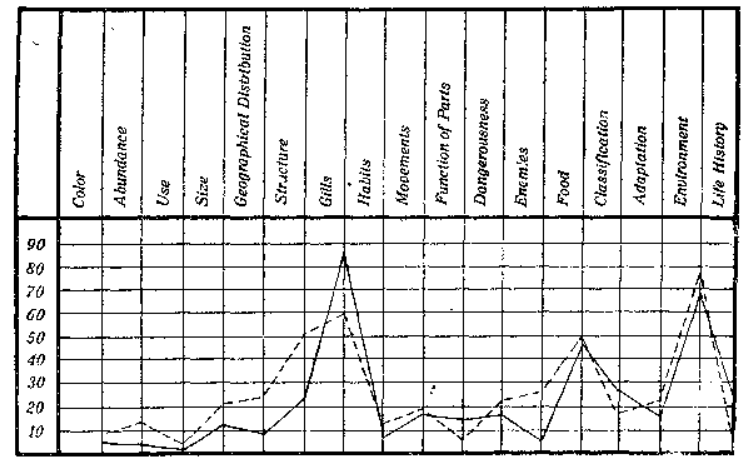

DrAgRAM 15.

Teleological Questions. Diagram 14. Under this head were classed such questions as, "Why has he such a flat head?"; "Why is his tail so long?"; "What has he four feet for?"'; "Why are his eyes so small?"; "What makes it have such funny little feet?" It will be noticed that from a scientific viewpoint these questions are unanswerable. No one knows, for example, why the mud-puppy has such a flat head any more than he knows why we have four fingers and a thumb. As compared to most animals 
the head is flat but as long as there have been any records available on the species the head has been flat and so far as is known no one has ever discovered why. One second grade teacher suggested that the questions were in reality interjections as, "What a flat head" ; "What funny little feet" ; and so on. This same teacher consistently confused function of structures with reasons for their existence. The curve shows a very definite falling off of interest in the upper grades in secking "reasons" for structural characteristics.

\section{A Check on the Experiment.}

In order to get some data which might serve as a check on this experiment another exercise was planned. The pupils in the fourth, fifth, sixth, seventh, and eighth grades of The University

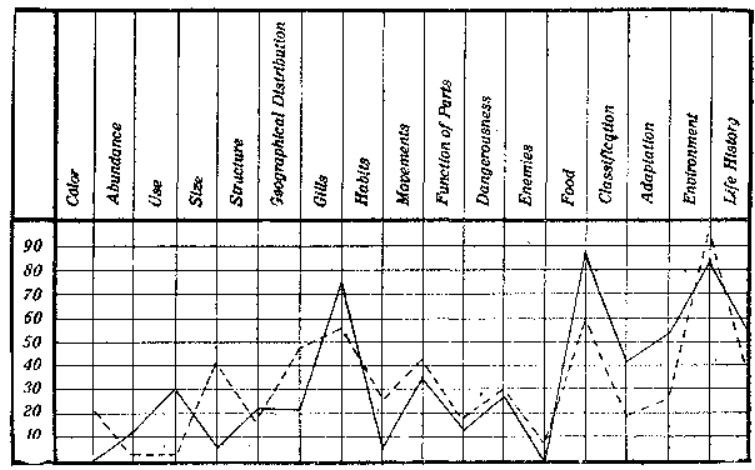

Diagram 16.

Elementary School were requested to write a composition on the mud-puppy just forty days after they had had the discussion on it. In the discussion all phases of interests manifested in the animal had received consideration, hence the pupils were exposed at least to facts concerning the animal. During the forty-day intermission no further work was given them on the animal. Neither pupils nor teachers knew that the written work was to be called for. As in the first experiment no questions or suggestions were permitted and no words were spelled for them the object being as in the original experiment that no suggestions be made which would stimulate added ideas to other pupils. In tabulating the results one count was given for each phase mentioned, regardless of the space given the phase in the discussion. It will be seen that this differs from the former tabulation in which each question was weighted thus making it possible for a single phase to receive more than one count. In many of the papers there was irrelevant material which was not tabulated. 
In the diagrams used to show the results of the tabulation dashed lines are used to indicate the distribution of the compositions, a continuous line, the questions asked in the original experiment. The horizontal lines indicate percentages, the vertical lines, phases of interest.

Because of similarity of results the graphs of the fifth and seventh grades will be shown, the rest omitted. In all the grades there was a remarkable similarity in the lines representing the compositions and the questions. The data seem to substantiate the idea that the pupils wrote about the phases on which they asked questions. The check thus supports the contention that in this experiment the children's questions are indicative of their interests.

\section{Pupils' Interests in Plants, Animals, and Physical Phenomena. \\ Purpose and Plan of the Work.}

The purpose of this experiment was to gather data relating to children's interests in the three phases of elementary science mentioned above. As in the preceding one the work was done in regular school hours, the plan bcing to give a class exercise in which each phase should be presented, each receiving as nearly as possible an equal amount of time and equally stressed in the presentation. At the close of the exercise a typewritten set of instructions concerning the further procedure were given the teacher. On the following school day the regular teacher was requested to call for a written exercise restricting the pupils to write on one phase only.

There are many possible sources of error in an experiment $\mathrm{cf}$ this type. In the first place it is not argued that the three phases chosen are of equal moment. Lacking proper standards of measurement we cannot say that each phase received a like amcunt of stress in the presentation. Perhaps the pupils in one school might be particularly interested in one phase because they had been Jearning much about it in their regular class work. The converse of this might equally well be true, namely that they were most interested in a phase because it had been omitted from their regular classroom work. Both these arguments were given repeatedly by teachers who participated in the work. However, it must be remembered that careful effort was constantly made to keep the three parts of the experiment well balanced and to give equal amount of stress to the presentation of each. 
It was planned to choose for presentation things which would be new or novel to most of the pupils. To represent the animals, a bird commonly known as the black-skimmer or scissors-bill was chosen. For the plant, a species of Bryophyllum commonly known as the life-plant was used while the pendulum represented the physical phenomena. These three things were presented in each exercise, eight to ten minutes being given each thus making the exercise of twenty-four minutes to a half hour's duration.

\section{Subject Matter and Method of Presentation.}

The bird. A mounted specimen of the black-skimmer was used. The class was told approximately the following: "The name of this bird is black-skimmer, (the words, "blackskimmer" were then written on the board). It gets its name from the color of its back, which you see is black, and from its habit of skimming over the water. It is an ocean bird and may be found on the Atlantic coast from Virginia southward and on the coast of the Gulf of Mexico. Notice the peculiar structure of the bill." They were then shown the remarkable bill of the bird, the two mandibles of which are very long and so thin that if a finger be held behind them in a bright light the outline of the finger can be easily seen. The lower mandible in the specimen used was about half an inch longer than the upper one. After the class had noted these things the pupils were told that, knowing the bird to be a water bird and knowing the peculiar strueture of the bill and the bird's habit of skimming over the water, they should be able to guess what the bird eats and how it gets the food. That the bird fed on fish was usually guessed at once. many guesses were required, however, before the correct manner of procuring the food was mentioned. The guesses usually given were, that the bird would pounce down in the water and capture its food as does the kingfisher, that it used its sharp bill as a spear and pierced the fish, that it would use its sharp bills as a pair of scissors cutting the fish in two and later picking the pieces up and eating them, that it would eatch the fish in its claws, carry the prey to the shore and eat it. In each exercise the correct method was guessed. The bird "skims" the surface with its lower mandible cutting the water. With its bill so placed it can scoop up minnows and small fish which swim at the surface.

The plant. In presenting the life-plant two living potted specimens were used, one a mature plant more than a foot high and the other a leaf which had been so planted that half of it pro- 
truded above the soil and which had given rise to two small shoots bearing six leaves each. They were told that the lifeplant grew in Mexico and that its name was life-plant (like in the preceding the name "life-plant" was written on the board). They were given as possible reasons for its name the fact that new plants could be grown from it by putting either its shoots or leaves in the ground. Before telling them this, however, they were asked to state as many ways as they could in which new plants might be secured from other plants. The following suggestions were usually given; by means of seeds, stem cuttings or slips, bulbs, tubers, grafts, underground roots, and underground stems. Following this they were shown the pot containing the leaf from which were growing the two new shoots. It was explained to them that very few plants would produce new ones in this way.

The pendulum. For this part of the experiment a rough piece of apparatus was constructed. For the base a board twelve by sixteen inches was used. To this base was nailed a sixteen-inch upright to which was fastened an arm projecting above the base and parallel to it. Through the free end of this arm was drilled a small hole in which a string might be raised and lowered and be held at any desired length by a wooden peg. A string to the lower end of which was fastened a small iron drawer pull constituted the pendulum. The pupils were told that this part of the exercise dealt with the pendulum and were told that the pendulum was the string with the iron weight that the rest of the apparatus was merely a support for the pendulum. As with the other two things the word, "pendulum," was written on the board. The following things were demonstrated, the pupils observing and doing the counting: That when once started the pendulum continued to go in the same direction, (plane); that with a given length of string the pendulum makes the same number of movements whether it goes through much space or little space, whether it goes in one plane or in a circle; that the shorter the string the more movements and the longer the string the less movements. Using the knowledge they had gained they were asked to guess the length of string required to make a pendulum which would make one swing in a second.

It will be seen that in each of the above exercises the pupils in the class participated.

School Types Used.

Three of the schools in which this experiment was tried were 
mentioned in the succeeding discussion, namely, The University Elementary School, the Gary school, and the Oak Park school. In addition to these there were two others.

Canton, Illinois. Canton is a small, manufacturing town in Illinois. It has a large per cent of foreign-born children in its schools. It had an excellently administered system with an exceptionally efficient corps of teachers. At the time the experiment was given, there was no definitely organized course of study in elementary science work but the subject was taught in all grades.

Training School of The Western Illinois State Normal School, Macomb, Illinois. The Supervisor of Teacher Training and most of the grade teachers in this school were intensely interested in elementary science and at the time of the experiment were engaged in formulating a course of study in it.

The grades concerned and the numbers of pupils in each are shown in the following table:

Schools, Grades, and Pupils Involved.

\begin{tabular}{|c|c|c|c|c|c|c|c|}
\hline & & 1 (1) & & & & & \\
\hline U. E.S. & $--{ }_{-1}$ & 39 & 40 & 30 & 25 & $\ldots$ & 134 \\
\hline Gary & 49 & 33 & 18 & 18 & 68 & & \\
\hline Oak Park & 30 & & 32 & 21 & 50 & 36 & \\
\hline $\begin{array}{l}\text { Canton } \\
\text { Macomb }\end{array}$ & $\cdots$ & 41 & 42 & 42 & 61 & $\begin{array}{l}22 \\
20\end{array}$ & $\begin{array}{r}208 \\
98\end{array}$ \\
\hline Macomb. & & 18 & 20 & 20 & 20 & & \\
\hline Total. & 79 & & & & & & \\
\hline
\end{tabular}

At the conclusion of the exercise the teacher in charge was given typewritten instructions as follows:

"On (name of day) will you please have a short, written exercise on this lesson.

"Have the pupils write only on one of the things presented, that is the plant, the animal, or the pendulum.

"In order that the pupil may have the three phases of the work in mind will you please write the following words on the board in this order:

"Be sure that the pupils' names and grades are on the papers.

"Do not let the pupils know before the time of the written exercise that they are to do this.

Tabulation of the Results.

The thing on which each pupil wrote was taken as indicative of the one most interesting to that pupil. In the following table 
the numbers given are the nearest whole per cent of pupils writing on that phase.

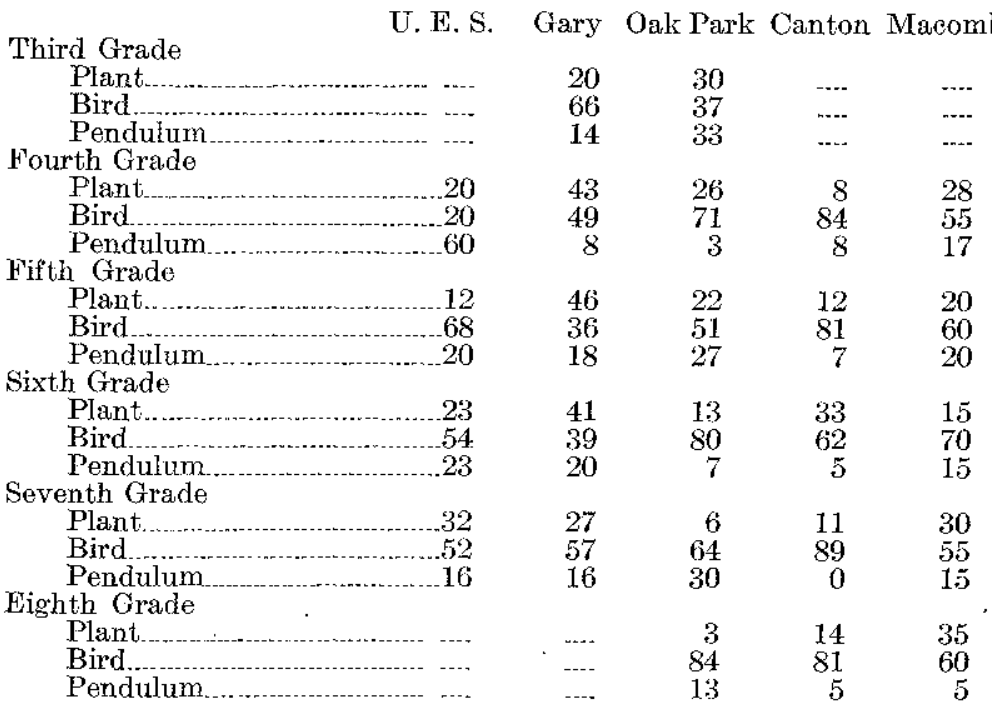

A perusal of the table shows that in twenty-two of the twentyfive classes listed the bird was the thing receiving most compositions by the pupils. The plant received most consideration in the fourth and fifth grades of the Gary school and the pendulum in the fourth grade of the Cniversity Elementary School. In the normal school at Macomb an additional check was given to see if additional evidence of interests might be secured. You will notice that in this school the bird fared best in each grade. Just two weeks after the exercises had been given the following request was made to the pupils "If Mr. Finley were to come to us today and discuss just one of the things he demonstrated to us two wceks ago which would you prefer? Write your choice on these slips of paper." The result:

$\begin{array}{lccccc} & \text { Fourth } & \text { Fifth } & \text { Sixth } & \text { Seventh Fighth } \\ \text { Plant } & 0 & 10 & 30 & 5 & 15 \\ \text { Bird } & 89 & 75 & 65 & 75 & 60 \\ \text { Pendulum......... } & 11 & 15 & 5 & 20 & 25\end{array}$

Sonn of the written commenis of teachers concerning the work and made at the time the exereises were given to their classes are interesting.

Fourth Grade, University Elementary Sohool:

Teacher- "The class was most interested in the bird. Interest rather low when plant was introduced, so many new facts having been brought betore the minds of the class." 
.Assistant-_-"Beyond doubt the class was most interested in and most will write about the plant." Refer to the table to see what actually happened.

Fifth Grade, University Elementary School:

Teacher-" "The pupils were most interested in the bird; they had studied it last year."

Fifth Grade, Macomb:

Teacher- "More interest in the pendulum."

Sixth Grade, U. E. S.:

Teacher- "Interested most in plant, second in pendulum."

Sixth Grade, Macomb:

Teacher-"Interest equal in pendulum and plant and greater in bird." An excellent guess.

Seventh Grade, U. E. S.:

Teacher-"Most questions were asked about the plant. Interest about same in all, possibly a little more in pendulum for they counted."

Effect of Order in Presentation on the Pupils' Responses.

In all save the University Elcmentary School the things were presented in the class exercises in the order shown in the following table.

\begin{tabular}{lcccccc} 
& Third & Fourth & Fifth & Sixth & \multicolumn{2}{c}{ Seventh Eighth } \\
Plant & 2 & 2 & 3 & 2 & 1 \\
Bird & 2 & 3 & 1 & 3 & 2 \\
Pendulum & 2 & 3 & 1 & 2 & 1 & 3
\end{tabular}

Inasmuch as the bird received most consideration in each grade the order in which the phases were given in the class demonstrations showed no effect on the pupils' responses.

Effect of Order of Suggestion on Pupils' Responses.

The "order of suggestion" refers to the order in which the names were written on the board. With the exception of the school mentioned above such order was as follows:

\begin{tabular}{|c|c|c|c|c|c|}
\hline Third & Fourth & Fifth & Sixth & Seventh & Eighth \\
\hline 2 & 3 & $\begin{array}{l}1 \\
2\end{array}$ & $\begin{array}{l}2 \\
3\end{array}$ & $\begin{array}{l}1 \\
2\end{array}$ & \\
\hline Gulum 3 & 2 & 3 & 1 & 3 & \\
\hline
\end{tabular}

For the same reason as mentioned above the order of suggestion showed no effect on the responses.

Comparison of Responses of Boys and Girls.

In the University Elementary School and the Gary School the boys' and girls' papers were tabulated separately with the result shown below. The numbers given indicate nearest whole per cent.

University Elementary School:

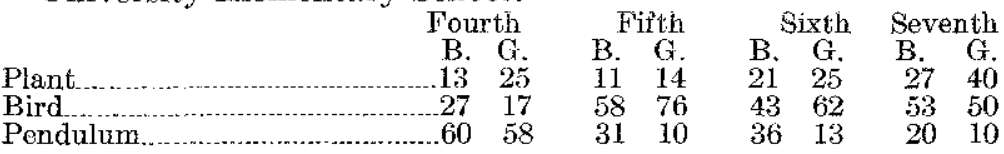


Gary School:

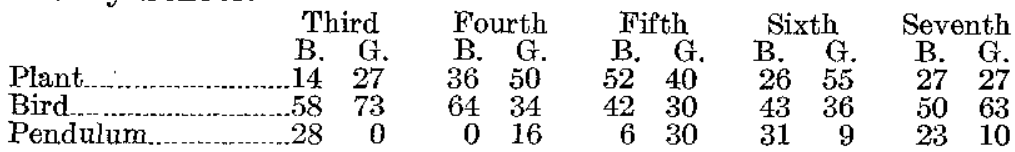

In seven of the nine classes listed above the boys and girls agreed in giving most of their compositions to the same thing. You will reeall that there were three classes in the whole twentyfive in which the bird failed to get most consideration. Two of these classes, the foirth grade in the first table and the fifth in the second, find both boys and girls in agreement in giving a preponderance to another phase.

In presenting this article the writer does not do it with the idea that it has in it startling and hitherto unknown facts but more with the hope that it will stimulate quantitative investigations in the teaching of elementary and secondary sciences.

\section{INTERSTATE TOWNS.}

There is an old story that many of the names of towns, sleeping cars, ete. were devised by a maniac who had a passion for writing letters on the walls of his cell in meaningless combinations. Travelers who attempt to pronounce some of the difficult names they see on cars are very much inelined to believe this story.

The appropriate names for new towns are often as hard to select as car names and some of those selected are apparently as meaningless and are as difficult to pronounce. For many of them, however, there is a reason. Many towns that lie partly in one State and partly in another, or close to the State line, have fine sounding and distinctive names that are made up of parts of the names of the two states. The following are names of this kind that appear on maps issued by the United States Geological Survey of the Department of the Interior:

Arizmo, Arizona-New Mexico.

Calada, California-Nevada

Calexico, California-Mexico.

(In the Mexican half of the town

the order is reversed and it is called Mexicali.)

Calneva, California-Nevada.

Calvada, California-Nevada.

Calzona, California-Arizona.

Colmex, Colorado-New Mexico.

Coluta, Colorado-Utah.

Delmar, Delaware-Marylund.

Kanorado, Kansas-Colorado.

In Texarkana, which is one of the largest towns on the list, the post office building is on the boundary line, one half in each State. Some other names of this elass not yet shown on Geological Survey maps are Alaga, Arkinda, Arkla, Dakoming, Texhoma, Urado, Wissota, and Wyuta.

It will be noted that this idea of combination appears to be particularly a southern and western one. North of Mason and Dixon's Line and east of the Mississippi it has not prevailed.- $[U$. S. Geol. Survey. 